\title{
Pathogenic Mechanisms in Sporadic Amyotrophic Lateral Sclerosis
}

\author{
Andrew Eisen and Charles Krieger
}

\begin{abstract}
ABSTRAC'T: In recognition of the 100th anniversary of Charcot's death we have reviewed possible pathogenic mechanisms in amyotrophic lateral sclerosis (ALS). Advances in the last 5 years in molecular biology and genetics have identified mutations in the cytosolic dismutase (SOD1) gene in some patients with familial ALS raising the possibility that oxidative stress may be involved in the pathogenesis. An excitotoxic pathogenesis has been implicated based on elevated plasma and CSF levels of amino acids and altered contents of amino acids in the nervous system of ALS patients and changes in the number of excitatory amino acid receptors. ALS sera containing antibodies to L-type calcium channels and the development of immune mediated lower and upper and lower motor neuron models have revitalized research efforts focusing on an immune basis for ALS. Other pathogenic mechanisms which have been the subject of recent research include elemental toxicity, apoptosis and programmed cell death and possibly a deficiency or abnormality in growth factors. Pathogenic processes for ALS must account for an increasing incidence of ALS, male preponderance, and the selective vulnerability of the corticomotoneuronal system.
\end{abstract}

RÉSUMÉ: Mécanismes pathogéniques de la sclérose latérale amyotrophique sporadique. En l'honneur du centième anniversaire de la mort de Charcot, nous avons revu les mécanismes pathogéniques possibles de la sclérose latérale amyotrophique (SLA). Les progrès effectués en biologie moléculaire et en génétique au cours des 5 dernières années ont permis d'identifier des mutations du gène de la dismutase cytosolique.(SODI) chez certains patients atteints de SLA familiale. Cette constatation soulève la possibilité qu'un stress oxydatif soit impliqué dans la pathogenèse de la maladie. L'hypothèse repose sur l'observation de taux élevés d'acides aminés dans le plasma et le LCR, d'un contenu altéré en acides aminés du système nerveux des patients atteints de SLA et de changements dans le nombre de récepteurs pour les acides aminés excitatifs. La découverte d'anticorps dirigés contre les canaux claciques de type $L$ et le développement de modèles de la maladie par atteinte immunologique du neurone moteur central et périphérique ont ravivé la recherche d'une cause immunologique de la SLA. Les autres mécanismes pathogéniques qui ont fait l'objet de recherches récentes sont la toxicité élémentaire, l'apoptose et la mort cellulaire programmée, et possiblement une déficience ou une anomalie de facteurs de croissance. Le processus pathogénique de la SLA doit expliquer une incidence accrue de la SLA, la fréquence plus élevée chez l'homme, et la vulnérabilité sélective du système neuronal corticomoteur.

Can. J. Neurol. Sci. 1993; 20:286-296

The cause of amyotrophic lateral sclerosis (ALS) is unknown despite the passing of more than 120 years since Charcot's original descriptions of the disease. ${ }^{1.2}$ It is 100 years since Charcot's death (1825-1893) and progress in ALS research has undergone rapid and often exciting advances in the last five years. It can be expected that the growth in understanding the disease will continue to accelerate making it timely to review possible pathogenic mechanisms that have evolved. Many of the suggested causes for ALS have acquired very compelling evidence for a pathogenic role. Perhaps the real challenge in ALS research lies in elucidating a new mechanism to satisfactorily explain the disorder or to adopt a wider view to unite the seemingly disparate evidence into a more cohesive framework.

ALS is devoid of a specific biochemical, or other, marker and diagnosis depends upon a clinical constellation which should include characteristic, but not specific, electromyographic abnormalities..$^{3 \cdot 6}$ An acceptable definition of ALS includes the following elements: 1) an essentially painless, progressive motor disease, involving both the upper and lower motor neurons; 2) seldom commencing before middle or later life; 3 ) occurring in the absence of a radiologically detectable structural lesion, and 4) that spares eye movements and sphincter function. There are obviously exceptions but isolated primary lateral sclerosis (PLS) and primary muscular atrophy (PMA) are best considered different diseases. ${ }^{7-9}$ The same is true of monomelic amyotrophy and postpoliomyelitis syndrome and ALS-like syndromes occurring within 12 to 24 months of a significant systemic disease, for example as has been described in association with lymphoma. ${ }^{10}$ The presence of multifocal motor conduction block, with or without anti-GMl ganglioside antibodies or other

From the Neuromuscular Diseases Unit, The Vancouver General Hospital and the University of British Columbia, Vancouver

Received March 17, 1993. Accepted in final form July 29, 1993

Reprint requests to: Andrew Eisen, M.D. The Neuromuscular Diseases Unit, The Vancouver General Hospital, 855 West 12th Avenue, Vancouver, British Columbia, Canada V5Z $1 \mathrm{M} 9$ 
antibodies clearly indicate a disease of the peripheral motor nerve and should be considered a different disorder." This review is directed to the pathogenesis of sporadic ALS.

There has been increasing interest in recent years in "overlap syndromes" in which patients have features of ALS, Parkinson's disease or Alzheimer's disease. The many aspects shared by these neurodegenerative diseases have been detailed elsewhere. ${ }^{12-15}$ The importance of overlap lies in the likelihood that insight into the pathogenesis of any one of these disorders will yield clues useful to the understanding of the others.

\section{A Genetic Component}

Familial ALS (FALS), inherited as an autosomal dominant trait, constitutes less than $10 \%$ of cases. Twin studies have not shown significant concordance for sporadic ALS. ${ }^{16}$ It remains to be seen to what extent the pathogenesis of familial ALS is fundamentally distinct. Nevertheless, a recent report has identified an abnormal gene in some families with ALS. This is possibly the most significant recent breakthrough in ALS research. ${ }^{17.18}$ In several pedigrees (11/13) with FALS a gene that mapped to chromosome $21 \mathrm{q}$ showed a tight linkage between FALS and a gene that encodes a cytosolic $\mathrm{Cu} 2+/ \mathrm{Zn} 2+$ - binding superoxide dismulase (SODI). ${ }^{18}$ SODI mutations might result in failure of detoxification of superoxide resulting in oxidative stress from excessive free radical accumulation. This in turn raises the potential for useful therapy with antioxidants. The potentially lethal effects of formation of highly reactive oxidizing species (i.e., oxygen free radicals) are normally neutralized by protective mechanisms that maintain cells in a reduced state, despite their aerobic environment. They include DNA repair enzymes, antioxidants, stress proteins and poly(ADP-ribosyl) polymerase. ${ }^{19}$ Age-related failure of their efficiency results in neuronal damage by shifting the cellular oxidation-reduction (redox) equilibrium toward oxidation. Oxidative stress may be important in the pathogenesis of a large variety of unrelated diseases and is presently a popular candidate hypothesis for the pathogenesis of Parkinson's disease. ${ }^{21}$ Formal trials in ALS patients using either vitamin $\mathrm{E}$ or deprenyl, which are commonly employed antioxidants in the therapy of Parkinson's disease, are lacking. However, in the authors' experience neither medication has been beneficial in ALS. We have encountered several patients developing ALS despite taking 400-800 iu of vitamin E for years prior to their first symptoms.

Also of interest is the recent report by Eubanks and co-workers that the gene encoding the glutamate receptor subunit, GluR5, is located on human chromosome $21 \mathrm{q}$ in the vicinity of the SODI gene. ${ }^{21}$ The significance of this finding is unclear as no study has established a linkage between this locus and a gene abnormality in FALS. There are a diversity of receptor subtypes through which synaptically released glutamate might produce insidious and progressive neuronal injury typical of ALS. The non-NMDA, AMPA/kainate subtypes are emerging as leading candidates. ${ }^{22}$ ALS cerebrospinal fluid contains a specific neurotoxic factor which is AMPA/kainate-like which when added to rat neurons in culture significantly reduced their survival..$^{22}$

\section{Epidemiological Clues}

Recent reports suggests that there is an increasing world wide incidence of ALS unrelated to an aging population. If this proves to be correct it would be consistent with an environmen- tal factor as being significant. ${ }^{23-27} \mathrm{~A}$ variety of possible risk factors have been associated with an increased incidence of ALS. They include mechanical and electrical injuries and vigorous physical activity including regular practice of sports in adulthood. ${ }^{27-32}$ Physical activity was also found to be a risk factor for one of a twin pair developing ALS. ${ }^{33}$ Physical activity is unlike$l y$, in and of itself, to cause ALS. The disease probably commences some time before clinical deficits become overt making it difficult to determine the time of its real onset and thus any significant correlation to trauma, physical labour or surgery. 3.35

With the exceptions of Guam, Western New Guinea and the Kii Peninsula of Japan, it is generally accepted that the incidence of ALS is uniform throughout the globe. This may not be true and for example its incidence in Mexico and Harris County, Texas is significantly lower than elsewhere $(<0.3$ per 100,000 population) ${ }^{36.37}$ Confirmation of a geographic variation is important; it too would support a role for an agent in the environment linked to the development of ALS. Alternatively variation in incidence might reflect differences in the susceptibility of populations to develop ALS. The previously high incidence of Guamanian ALS has steadily decreased over the last decade suggesting a reduced exposure to an environmental agent, possibly ingestion of cycad. ALS continues to be prevalent but patients are mostly long-term survivors ( $>10$ years disease duration). ${ }^{38}$ The Guamanian disease shares many of the features of Western sporadic ALS. There are also enough differences to preclude the assumption that the Western and Guamanian disease are the same. In the last 2-3 years research on the island of Guam has been intensified. ${ }^{39}$

Clustering of ALS would be another factor supporting an environmental pathogenesis. Several clusters have been described but they have all been small and a statistically significant cluster of ALS has yet to be reported. ${ }^{27.40-42}$

\section{Pathological Clues}

Knowledge is lacking as to whether the descending corticospinal pathways (corticomotoneurons) or lower motoneurons are initially involved in ALS; or whether death of each occurs independently of the other. Convincing arguments favouring retrograde degeneration of the corticospinal tracts resulting from primary disease of the anterior horn cell have been put forward. ${ }^{43.44}$ This was not Charcot's view. ${ }^{45}$ He postulated that it was the upper motor neuron that was the first to be involved and that the demise of the anterior horn cell followed ("corticomotoneuronal hypothesis"1.3). The idea that degeneration of the lower motor neurons in ALS is due to antegrade transneuronal events secondary to loss of corticomotoneurons has been recently revisited. ${ }^{13,46,47}$

In addition to cortical cell loss seen on routine pathology there are several other lines of evidence to implicate the motor cortex. For example, aberrations in brain ganglioside profiles have been detected in many $(>80 \%)$ patients. ${ }^{48}$ The same ganglioside abnormalities are not seen in the spinal cord suggesting that the primary pathology is in the brain. Gangliosides are major membrane constituents whose carbohydrate residues establish structural configurations on the external face of the cell membrane. It is likely that aberrant ganglioside patterns reflect alterations in receptor structure and function which are inherently cell specific. ${ }^{48}$ 
Signal loss in the motor cortex on high-field magnetic resonance imaging in ALS is also of interest in the context of an upper motor neuron hypothesis. These radiological abnormalities have been interpreted as reflecting iron deposition secondary to degeneration of the pyramidal tract ${ }^{49.50}$ Kiernan and Hudson, ${ }^{51}$ who re-initiated the upper motor neuron hypothesis, failed to show a correlation between a loss of pyramidal cells of the foot and tongue area and corresponding anterior horn cells in ALS. However, this might have been anticipated given that there is not a one to one relation between corticomotoneurons and anterior horn cells. ${ }^{52}$

There is no natural or experimentally induced animal model that completely mimics human ALS, ${ }^{53}$ the main difficulty being the failure to induce both upper and lower motor neuron deficits. The transgenic mouse model recently reported by Cote and colleagues has some characteristic elements of ALS. ${ }^{54}$ The disease is progressive and does not manifest until after the first few weeks of postnatal life, however, there is no evidence of upper motor neuron involvement.

The complexity of the human corticomotoneuronal system compared to other animals is impressive and may be a clue to the etiopathogenesis of ALS. There are monosynaptic connections to all motor neuron pools except the motorneurons of the extraocular and Onuf's nuclei. ${ }^{55}$ With rare exceptions these are spared in ALS. ${ }^{56.57}$ The main neurotransmitter of the corticomotoneuronal system is likely to be glutamate or aspartate..$^{58}$ The distribution of $\mathrm{N}$-methyl - aspartate (NMDA) receptors in the normal human brainstem nuclei has been investigated using quantitative autoradiography with tritiated MK-801.58 Those nuclei subserving eye movements have significantly lower densities of specific MK-801 binding compared to other cranial nerve motor nuclei suggesting that they might receive less corticomotoneuronal input. ${ }^{58}$ These findings support the corticomotoneuronal hypothesis.

Large proximal swellings (spheroids) which are continuous with the motor neuron perikaryon occur in about $70 \%$ of cases of ALS; they are particularly prominent when disease duration is brief. ${ }^{59,60}$ However, they are not specific to ALS. They are seen in the brain stem motor nuclei and corticospinal tracts but not the motor cortex. ${ }^{61}$ There is also a significant increase in the diameter of the axonal initial segment in ALS, ${ }^{62}$ which may represent the earliest sign of spheroid formation. Spheroids consist of accumulations of neurofilaments which immunocytochemically have the epitopes of normal axons. ${ }^{63}$ It is unlikely that spheroids have a major pathogenic role in ALS but the disruption they cause might influence the synthesis, degradation or transport of neurofilamentous subunits. ${ }^{64-66}$

Accumulations of neurofilaments are frequently observed in the neurons in ALS. Neurofilaments are neuron-specific cytoskeletal elements composed of 3 subunits of molecular mass $200 \mathrm{kd}, 145 \mathrm{kd}$ and $68 \mathrm{kd}$ (NF-H, NF-M and NF-H) respectively. ${ }^{67}$ Neurofilaments determine axonal caliber and are associated with axonal transport, which is abnormal in ALS. ${ }^{64}$ As neurofilamentous changes became incriminated in ALS the effects of overexpression of their subunits was evaluated using transgenic mice. ${ }^{68}$ Transgenic mice are unique in that neurofilament expression can be linked to a phenotype suggesting a causal relationship between the overproduction of neurofilament protein and the resulting clinical and pathological features. For example, recent studies in which increased amounts of NF-L were produced in peripheral neurons have resulted in a mouse model with clinical and pathological features having parallels to ALS. ${ }^{69}$ Other transgenic lines with increased expression of NF- $L$ were smaller and less active than normal mice and died by 3-4 weeks of age. Their motoneurons were chromatolytic with massive accumulations of neurofilaments. ${ }^{69}$ Affected mice also had axonal degeneration and proximal axonal swellings. Transgenic mice with overexpression of NF-H protein also develop progressive weakness and gait difficulty associated with swollen perikaraya and proximal axons and atrophy of distal axons. Similar changes were noted in the dorsal root ganglia. The swellings were demonstrated to be abnormal accumulations of neurofilaments. ${ }^{54}$

Cytoskeletal changes associated with clinical and pathological features of motoneuron death are seen in several well established mouse mutants, e.g., the wobbler mouse ${ }^{70}$ and the MND mouse. ${ }^{71}$ The nature of the underlying process producing the neurofilamentous change in ALS remains unclear. Simplistically, the accumulation of neurofilaments could be due to increased synthesis, decreased degradation or impaired axonal transport of a neurofilamentous subunit. ${ }^{69}$

Microscopic pathology of the spinal cord and the motor cortex in ALS has suggested that a very early abnormality is depletion of dendritic neurofilaments leading to dendritic atrophy and breakage. This in turn might lead to shrinkage and preferential death of the perikaryon. ${ }^{2}$ Spinal, corticomotoneuronal and cortico-bulbar neurons contain conspicuous bundles of neurofilaments in their dendrites which could explain the selective vulnerability of these neurons in ALS. Whatever it is that underlies neuronal degeneration in ALS it does not compromise the neuron's capacity for vigorous expression of growth-associated proteins such as GAP-43. ${ }^{73}$

Ubiquitin is a highly conserved low-molecular-weight, heat shock protein implicated in the nonlysosomal degradation of short-lived and abnormal proteins. ${ }^{65}$ Ubiquitin-immunoreactive inclusions, which do not correspond to inclusions seen in light microscopic studies, are common, if not invariable in anterior horn cells in ALS. They may be most prominent early in the disease $^{74}$ and also occur in the cranial motor nuclei but rarely in the oculomotor nuclei. Somewhat different but related (skein-like or granular) ubiquitin-immunoreactive inclusions have also been seen in the motor cortex ${ }^{75-77}$ and specifically the giant cells of Betz in ALS. ${ }^{78}$ Ubiquitin-positive intraneural inclusions have also been seen in cortical regions outside of motor cortex in ALS patients ${ }^{79}$ and in patients with the Guamanian ALS-PD complex. ${ }^{80} \mathrm{It}$ is not clear whether ubiquitin accumulates as part of a nonspecific "stress response" or reflects abnormalities of the ubiquitin pathway thereby contributing to neuronal damage.

\section{Clinical Clues}

The spread of ALS symptoms within spinal cord segments appears to be a function of the distance between the original site and sites of subsequent dysfunction. Time for contiguous areas to become involved is shorter than for non-contiguous areas. ${ }^{81}$ Spread to non-contiguous areas is faster within the spinal cord than from the spinal cord to the bulbar region and the time to spread from the arm to the brainstem is shorter than from the leg to the brainstem. The mechanisms that underlie this pattern of spread in ALS are uncertain but might involve axonal transport. ${ }^{81}$ The pattern of spread might also reflect extrusion, by 
dying neurons, of toxic materials that in turn affect neighboring neurons.

There may also be a gender effect on the spread of symptoms in ALS. ${ }^{81}$ In men, spread to the limbs following bulbar onset is more rapid than for women. In women there is a more rapid onset of dysfunction in an opposite leg, either arm or bulbar involvement after leg onset. Male preponderance for ALS is universally observed ${ }^{27}$ and raises the possible role of sex hormones in the pathogenesis. Women developing ALS have a later menarche and earlier menopause so that the reproductive period is shorter. ${ }^{28}$ The role of androgens in motor neuron function is poorly understood but there is good experimental evidence that the motor neuron is an androgen target tissue and androgen accumulates in motor neurons that are preferentially affected in ALS. ${ }^{82.83} \mathrm{X}$-linked spinal and bulbar muscular atrophy (Kennedy's syndrome) is a motor neuron disease associated with androgen insensitivity, ${ }^{84}$ and causes androgen receptor gene mutations with an increased number of tandem CAG repeats in exon 1. A strong correlation between the number of CAG tandem repeats and clinical phenotypic expression has been recently demonstrated indicating that androgen gene mutation is directly involved in the degeneration of motor neurons. ${ }^{85}$

A remarkable feature of ALS is the apparent resistance to bed sores even in the face of severe paralysis and muscle wasting. Recent studies have shown that there is an increase in immature soluble collagen in the tissue and the cross-linking pathway of skin collagen runs counter to its normal aging resulting in a rejuvenation phenomenon in ALS. ${ }^{86.87}$ The finding appears to be specific for ALS and might be one future means of early detection.

\section{Excitotoxicity}

Glutamate, aspartate and possibly other acidic amino acids are thought to be neurotransmitters at the majority of excitatory synapses in the human nervous system including the corticospinal tracts. ${ }^{88}$ Synaptic responses evoked by these excitatory amino acids (EAA) are mediated by different EAA receptor subtypes named on the basis of the prototype agonist, e.g., $\mathrm{N}$-methyl-D-aspartate (NMDA), kainate (KAI) and alpha-amino3-hydroxy-5-methylisoxazole-4-proprionic acid (AMPA), as well as other receptor subtypes. ${ }^{89-91}$ There is considerable evidence from both in vivo or in vitro studies that administration of EAA to neurons with EAA receptors can lead to neuronal death. ${ }^{89}$ The mechanism of cell death depends on the EAA administered and its effects on the the various subtypes of EAA receptor. It is thought that $\mathrm{KAI}$ and $\mathrm{AMPA}$ cause an influx of $\mathrm{Na}^{+}$and $\mathrm{Cl}^{+}$leading to cell swelling which may be irreversible. Agonists acting at the NMDA receptor cause neuronal death by increasing the influx of calcium and other ions. ${ }^{89}$ The calcium influx leads to increases in intracellular free calcium concentration which activates calcium-dependent proteases (calpains), phospholipases and other enzymes which may lead to neuronal death. ${ }^{92}$ Excitatory amino acid receptors are present on mammalian motoneurons. ${ }^{93.94}$ Glial cells may play a role in modulating the effects of EAA. ${ }^{95}$

Excitatory neurotoxic compounds have been suggested as a possible cause of sporadic ALS, ${ }^{96.97}$ as well as for the ALSparkinsonism-dementia complex observed in the Mariana Islands. ${ }^{98}$ In sporadic ALS, concentrations of glutamic acid have been reported to be elevated in fasting plasma, ${ }^{96}$ and concentrations of glutamate, aspartate and $\mathrm{N}$-acetylaspartate as well as the dipeptide $\mathrm{N}$-acetylaspartylglutamate have been reported as increased in cerebrospinal fluid (CSF). ${ }^{99.100}$ Plasma cysteine concentrations have also been reported as increased in patients with sporadic ALS, and impaired sulfoxidation or sulfation of toxic thiol products postulated to be involved in the pathogenesis of ALS. ${ }^{101}$ However, the results of other workers have not supported some of these claims. ${ }^{102-105}$ Concentrations of quinolinic acid (QUIN), an endogenous NMDA agonist are not elevated in the CSF or in spinal cords from ALS patients.

Intrathecal injections of excitotoxins such as kainic acid and NMDA into rats can induce degenerative neuronal changes in spinal cord. ${ }^{106.107}$ Although NMDA effects occur both in the dorsal and ventral grey matter, intrathecal kainic acid produces grey matter lesions which are mainly located in the ventral horn of the spinal cord and these lesions include motoneuron degeneration with swollen cytoplasm and proximal neurite enlargements. ${ }^{107}$

Strong evidence that ALS or other human motor neuron diseases could arise from the action of excitotoxin(s) comes from clinicopathological observations of patients following the ingestion of mussels contaminated with the neurotoxin, domoic acid. ${ }^{108}$ Domoic acid has similar properties to kainic acid and binds to kainic acid receptors in rat hippocampus. ${ }^{(0)}$ Among the consequences of domoic acid intoxication were electromyographic features suggestive of acute denervation in patients who had been intoxicated and these changes were observed within one month after ingestion. These electromyographic abnormalities could be detected in milder forms for more than 1 year after intoxication and were interpreted to indicate a non-progressive motor neuronopathy or axonopathy. ${ }^{108}$ This might indicate that EAAs could produce motor neuronopathies in humans. No neuropathological abnormalities were found in the brain stem or thoracic spinal cord motor nuclei in the one patient in whom these regions were examined.

Four independent studies ${ }^{110-113}$ of the amino acid contents of autopsied spinal cords from patients who have died with ALS have demonstrated decreased contents of glutamate in cervical segments, ${ }^{110}$ or of both glutamate and aspartate in cervical and lumbar spinal cords regions. ${ }^{112.113}$ Contents of glutamate and aspartate are reduced in most brain regions in patients dying with ALS, ${ }^{110.112}$ while brain taurine contents are increased. As glutamate and aspartate contents largely reflect the amount of these substances in the intracellular compartment, the reduced levels of glutamate and aspartate might indicate a reduced neuronal pool of these substances. Two possibilities for a reduction of neuronal aspartate and glutamate contents could be neuronal death or excessive synaptic release. ${ }^{97.112}$ Plaitakis and colleagues $^{112}$ have attributed the reduced brain and spinal cord contents of glutamate and aspartate to increased release of EAA from nerve terminals with possible consequent neuroexcitotoxic damage to motoneurons. To explain the specific regional pathology of ALS, Plaitakis has further suggested that a potentiation of NMDA effects may be mediated by glycine on spinal motoneurons and bulbar sites in ALS patients. ${ }^{97}$

One possible mechanism which might produce excitotoxic damage is deficient transport of a normally released, endogenous EAA out of the synaptic cleft. As the major mechanism which is thought to limit the action of EAA on synapses is removal from the extracellular space by sodium-dependent 
transport systems it is possible that deficient transport would raise synaptic concentrations of EAA and produce excitotoxicity. EAA transporters are present on neuron and glial cells, however, it is not clear whether uptake is primarily by neurons or glial cells and how prevalent other mechanisms are for EAA uptake in the mammalian nervous system.

Evidence for defective transport of EAA by the high-affinity glutamate transporter has recently been reported to be present in the brains and spinal cords of ALS patients, but not in patients with Alzheimer's disease, Huntington's disease or in normal controls. ${ }^{116}$ In ALS patients there is a decrease in the velocity of transport of high-affinity uptake in synaptosomal preparations from affected regions such as spinal cord, motor cortex and somatosensory cortex but not in unaffected brain regions such as visual cortex, striatum or hippocampus. No differences in the velocities of sodium-dependent transport of either gammaaminobutyric acid or phenylalanine were detected in tissue from ALS patients. ${ }^{116}$

A recent study by Allaoua and colleagues ${ }^{114}$ has demonstrated that in ALS the distribution of binding for the radiolabeled ligands $\left[{ }^{3} \mathrm{H}\right] \mathrm{TCP} / \mathrm{NMDA},\left[{ }^{3} \mathrm{H}\right] \mathrm{AMPA}$ and $\left[{ }^{3} \mathrm{H}\right] \mathrm{KAI}$ in the cervical and thoracic segments of spinal cord is unchanged compared to controls. The densities of $\left[{ }^{3} \mathrm{H}\right] \mathrm{TCP} / \mathrm{NMDA}$ receptors were decreased both in the dorsal and ventral horns while the density of $\left[{ }^{3} \mathrm{H}\right]$ AMPA receptors were normal. The selective reduction in $\left[{ }^{3} \mathrm{H}\right]$ TCP/NMDA receptor number in ALS suggests that should an excitotoxic mechanism be involved in the pathogenesis of ALS, then NMDA receptors may be the target of this effect. ${ }^{115}$ These findings are of considerable interest as they could explain how normal synaptic concentrations of an NMDA receptor agonist could lead to reductions in NMDA receptors or NMDA receptor down regulation. Potentially, excitotoxicity could develop if uptake of an excitotoxin was impaired. For instance, if the putative excitotoxin producing ALS was a selective agonist at one of the subtypes of EAA receptor, a specific reduction in receptor subtype might be observed as a consequence of neuronal death subsequent to receptor activation.

Mammalian motoneurons possess NMDA receptors ${ }^{115}$ and since all of the spinal cords from ALS patients had motoneuron loss, reductions in NMDA receptor binding in the ventral horn could be interpreted as reflecting death of NMDA receptorbearing motoneurons. Surprisingly however, an equally pronounced reduction in NMDA receptor binding has also been found in the dorsal horn. Since afferent pathways are typically spared in ALS, both clinically and pathologically, it appears unlikely that the reduction in receptor binding is due to cell loss in the dorsal horn. A more likely explanation is that a downregulation of NMDA receptor number could occur in ALS, possibly due to the continued presence of increased amounts of an NMDA agonist in various spinal cord regions. ${ }^{114}$

If the NMDA receptor depletion is confined to motoneurons and interneurons, then a possible mechanism for this different pattern of NMDA receptor loss could be a potentiation of the neurotoxic effect of an NMDA agonist by concurrently released glycine. ${ }^{97}$ The glycine receptor which modulates NMDA action is insensitive to strychnine antagonism and is distinct from the well established strychnine-sensitive inhibitory action of glycine. ${ }^{117}$ Previous studies of strychnine-sensitive glycine receptors using quantitative receptor autoradiography in spinal cords from patients dying with ALS have demonstrated reduced numbers of receptors especially in lamina 9 (the motoneuron containing regions) compared to controls. The reductions in strychnine-sensitive glycine receptors were highly correlated with the degree of motoneuron loss found in the ALS patients. ${ }^{118}$

Despite the attraction of glutamate excitotoxicity, NMDA receptors are widespread in the nervous system, making it difficult to explain the selective vulnerabilty of upper and lower motoneurons characteristic of classical ALS. In the event that neuroexcitotoxic compounds are involved in the pathogenesis of ALS, administration of antagonists acting at EAA receptors might arrest or slow the clinical course of ALS. Presumably to be optimally effective, EAA receptor antagonists would have to be given early in the disease before motoneuron losses became extensive. In a recent study, mutant mice having a spinal muscular atrophy-like syndrome (wobbler mice) were treated with the NMDA antagonist, MK-801 for 12 weeks, in high doses but there was no clinical evidence for an arrest of the motoneuron losses which occurs in this mouse model. ${ }^{119}$

\section{ALS: An Immunopathy?}

A group of dysimmune-motor neuronopathies, associated with multifocal motor conduction block, and which mimic PMA have been identified. Some may respond to immunosuppression. Multifocal motor conduction block is essential for the diagnosis of dysimmune neuropathy and high titers of $1 \mathrm{gM}$ anti-GMl antibodies are commonly but not invariably found. ${ }^{120}$ Although the possibility of an immune mechanism has been raised in ALS many of the features of conventional autoimmune disorders are lacking. They include: 1) a lack of inflammatory infiltrate on pathological examination. 2) normal levels of the cytokines such as interleukin-6, which would reflect a tissue response to inflammation $^{121}$ and 3) a failure of improvement following immunosuppressive therapy. ${ }^{122}$ Nevertheless, several recent developments suggest that immunological dysfunction may play an important role in ALS. ${ }^{122}$

McGeer and colleagues detected abundant reactive microglia expressing the major histocompatibility glycoproteins HLA$A, B, C$ and HLA-DR in the spinal cord and motor cortex of ALS patients. ${ }^{123}$ Similar observations have been made by others. ${ }^{124-126}$ The same immunological abnormalities have been identified in Parkinson's and Alzheimer's diseases so that they are not specific to ALS. ${ }^{123}$ Related to these observations is a unique pattern of astrocytosis in ALS motor cortex noted in all of 22 patients who had upper motor neuron signs. ${ }^{127}$ The astrocytosis was characterized by multiple clusters of astrocytes, some of which showed a close association with macrophages. Intriguing as these observations are they may only reflect secondary changes.

Appel and colleagues have developed animal models of immune-mediated lower motor neuron destruction ${ }^{128}$ and gray matter disease, a model of both upper and lower motor neuron degeneration. ${ }^{29}$ High titers of antibodies to motoneurons are present, and result in enhanced release of acetylcholine from axon terminals at the neuromuscular junction. Long-term neuromuscular dysfunction in the mouse has also been induced by passive transfer of ALS immunoglobulin. ${ }^{130}$ Axonal degeneration and denervation was observed in most of the treated muscles; these effects could reflect an early stage in the immune-mediated pathogenesis of ALS. The effect of ALS immunoglobulin (IgG) on dihydropyridine-sensitive $\mathrm{Ca}^{++}$channels in mammalian skeletal muscle fibers, has also been studied and been found to produce a reduced $\mathrm{Ca}^{++}$current.$^{131}$ 
Electrophysiological studies have demonstrated that immunoglobulins from patients with ALS alter synaptic release by acting on presynaptic calcium channels. ${ }^{132}$ Antibodies to L-type calcium channels are present in the sera of patients with ALS and antibody titres correlate with the rate of disease progression. However, serum antibodies to voltage-dependent calcium channels (VDCC) are not specific for ALS since they are found in sera from patients with Lambert-Eaton syndrome. ${ }^{132}$ It is not clear whether L-type channels are the sole target of ALS immunoglobulin and what the relation is between this antibody and motoneuron death. Three possible explanations for the increased frequency of miniature endplate potentials (mepp) and the partial blockade of L-type VDCC are: 1) an increase in intracellular calcium; 2) a modification of existing VDCC and, 3) internal calcium release by antibody. ${ }^{132}$

The presence of immunoglobulin to VDCC in the sera of patients with ALS might suggest that involved neurons would not be confined to motoneurons and corticomotoneurons but that involvement would be more widespread. ${ }^{133} \mathrm{~A}$ factor which might confer selective vulnerability on motoneurons and corticomotoneurons is a relative paucity of calcium binding proteins. Immunocytochemical studies have demonstrated that motoneurons have only small amounts of calbindin D28K and parvalbumin immunoreactivity suggesting that their ability to buffer calcium using these calcium binding proteins is limited. ${ }^{134}$ Another possibility is that the distribution and type of VDCC may be different between corticomotoneurons, motoneurons and other neuronal types.

\section{Neurotrophic Factors}

Cells are continuously exposed to a variety of internal and external stressors (UV and gamma radiation, heat, oxygen free radicals, glucose, bacteria and viruses). Interconnected mechanisms which constitute a network of cellular defences have evolved to counteract these deleterious agents; they include DNA repair enzymes, heat shock and other stress proteins, enzymatic and non-enzymatic antioxidant defence systems and poly (ADP-ribose) polymerase activation. Age-related failure of these mechanisms may have profound effects on cell proliferation and cell death, two phenomena that are tightly linked and regulated. ${ }^{135.136}$

Apoptosis (programmed cell death) is part of the normal phenomenon in developing and possibly in some pathological settings. Many motor (and sensory and sympathetic) neurons die during a critical stage of development; their survival depends upon the presence of neurotrophic factors. Growing axons may compete for a limited amount of neurotrophic factors and those that fail to obtain a sufficient supply may die. Deprivation of growth factors induces an active process of programmed cell death. In contrast to necrosis, apoptosis is gene-directed. ${ }^{137.138}$ The dying cell is usually characterized by an increase in cytosolic $\mathrm{Ca} 2+$ which activates a non-lysosomal $\mathrm{Ca} 2+$ and $\mathrm{Mg}(2+)$ dependent endonuclease activity resulting in DNA fragmentation. ${ }^{139}$ Stewart and Appel ${ }^{140}$ have hypothesized that although the primary insult in the degenerative diseases (ALS, Parkinson's disease and Alzheimer's disease) may be multifactorial, the secondary effect is the result of retrograde degeneration occurring because of impaired trophic factor function.

The regulation of motoneuron number during development appears to be controlled by retrograde trophic factors from muscle. ${ }^{141.142}$ For example, in vertebrate embryogenesis the extent of naturally occurring cell death of the motoneuron pool may be modified by changing the amount of embryonic muscle available for innervation (the peripheral field) or by administration of agents which interfere with the capacity of the neuron to functionally innervate muscle, such as botulinum toxin. 14.3 Results from these studies have been interpreted as supporting a competition by motoneurons for a limited quantity of trophic substance.

Further evidence for this hypothesis has been based on studies usually involving the survival of cultured neurons or motoneurons, ${ }^{144}$ in the presence of muscle extracts, muscle conditioned media or purified neurotrophic molecules. ${ }^{145-147} \mathrm{~A}$ number of substances have been identified which support the growth of spinal cord neurons or motoneurons in vitro. Among the purified proteins which produce motoneuron survival in vitro are basic fibroblast growth factor (bFGF); ${ }^{146} \mathrm{CNTF}^{146}$ and cholinergic differentiation factor (CDF) which is identical to leukemia inhibition factor (LIF) (CDF/LIF). ${ }^{147}$

Evidence has accumulated demonstrating that the ncurotrophic effects of CNTF are observed not only in cultured motoneurons but during the embryogenesis of vertebrate motoneurons ${ }^{148}$ and in murine models of motor neuron discase (see below). Both CNTF and CDF/LIF act on the same receptor, which has homology to the receptor for the cytokine, interleukin-6. ${ }^{149}$ The CNTF;CDF/LIF receptor has been cloned and is expressed almost uniquely within the nervous system. CNTF receptor activation leads to signalling though a transduction pathway involving a component associated with the interleukin-6 (IL-6) receptor (gp /30) producing tyrosine phosphorylation reactions which differ from those induced by IL-6. ${ }^{150}$ The CNTF receptor appears to share several receptor components with CDF/LIF, however is also associated with activation of a third receptor component CNTFR-alpha which is largely restricted to tissues of the nervous system.$^{151}$

The CNTFR-alpha gene appears to be necessary to permit CNTF activation of signalling pathways. ${ }^{151}$ The pathways involved in CNTF signalling are poorly understood at present. mRNA for CNTF has been reported to be absent from skeletal muscle, initially casting doubt on whether CNTF could be a retrogradely-transported neurotrophic agent. ${ }^{152}$ Recent studies have indicated that small amounts of CNTF transcripts are detectable in muscle. ${ }^{151}$

CNTF has been shown to slow the progression of neuromuscular dysfunction in several mutant mice strains including the progressive motor neuron disease mouse, ${ }^{153.154}$ and the wobbler mouse. ${ }^{155.156}$ In the wobbler mouse CNTF increases the mean grip strength. Phase 1 and 2 trials in humans using recombinant CNTF are ongoing in North America and have shown that subcutaneous CNTF administration can achieve presumptive therapeutic levels without toxicity. ${ }^{157}$

Basic fibroblast growth factor (bFGF) has some motoneuron survival effects in vitro, but appears to be less effective than CNTF or CDF/LIF. ${ }^{148}$ It has not been clarified whether all the survival-promoting activity of muscle extract for cultured motoneurons resides in the activities of CNTF, LIF/CDF and bFGF, or whether other presently uncharacterized musclederived factors are also involved. ${ }^{158}$

\section{Viruses and ALS}

A number of different viruses have been related to human motor neuron syndromes but none have been definitively isolated 
from classical ALS. ${ }^{159}$ Attempts to extract a "slow transmissible agent" akin to that of Creutzfeldt-Jakob disease has also been unsuccessful. 160 Reports that ALS is a consequence of prior poliomyelitis have largely been anecdotal and have not been substantiated. Recent evidence argues against the hypothesis that poliovirus persists in patients with postpolio syndrome. ${ }^{161}$

The mouse leukemia virus and the human T-cell lymphotropic virus, both retroviruses, can cause lymphoma. There has been a recent report of the association of lymphoma in 9 patients with motor neuron disease. ${ }^{10}$ However, only 2 patients and $4 / 25$ others from the reviewed literature had ALS, i.e.; both upper and lower motor neuron features. Therefore a cause-effect relation remains to be proven.

\section{Elemental Toxicity and ALS}

Many naturally occurring elements have attracted interest at various times as being important in the pathogenesis of ALS. ${ }^{162}$ However, with few exceptions results of studies reporting abnormal elemental levels in ALS tissue have not been confirmed. The relationship between calcium and magnesium deficiency and resulting aluminum and possibly manganese toxicity remains of interest. A chronic dietary deficiency of calcium and magnesium with an excessive intake of aluminum and manganese has been implicated in the pathogenesis of high incidence ALS in Guam and the Kii Peninsula of Japan. 163-165 Calcium-magnesium dysmetabolism with resultant deposition of aluminum and manganese has also been reported in cases of sporadic ALS. ${ }^{166-168}$ Aluminum may induce a calcifying degeneration in ALS tissue leading to calcium-hydroxyapatite formation as the final chemical compound. ${ }^{165}$ Monkeys fed a diet low in calcium and high in aluminum developed pathological changes in the spinal cord, brain stem, substantia nigra and spinal cord similar to those seen in ALS-PD on Guam. These pathologic changes far exceeded those found in normal aged monkeys. ${ }^{169}$ Intracisternal inoculation of rabbits with low-dose $(100 \mu \mathrm{g})$ aluminum induces aggregates of phosphorylated neurofilaments that mimics the intraneuronal inclusions of ALS. ${ }^{170}$

\section{Conclusions and a Note on Therapy}

This review underscores that pathogenic mechanisms in ALS are complex, multifactorial and often inter-related. Despite the immense amount that has been accomplished in recent years realistically it will take time to piece together the bits of the puzzle. Based upon the pathogenic mechanisms discussed above several rational strategies are worthy of consideration. They include therapy with growth factors, glutamate antagonists and antioxidants. Even though conventional immunosuppression has not been beneficial in ALS there are several experimental immunosuppressants that may be effective.

We have alluded to the CNTF trial now underway in North America. ${ }^{157} \mathrm{CNTF}$ is probably the most potent of available growth factors in terms of motor neuron protection and survival. Preliminary studies suggest that it is safe in assumed therapeutic doses but may have unforseen side effects.

Lamotrigine 13,5-diamino-6(2,3 dichlorophenyl)-1,2,4triazine] is a phenyltriazine compound originally synthesized as one of a sequence of folic acid antagonists which has been recently licensed for use in the U.K. and Ireland as an anticonvulsant in refractory epilepsy. ${ }^{171}$ It acts mainly to inhibit excitatory amino acid (glutamate) release and stabilizes neuronal membranes via blockade of voltage-sensitive sodium channels. It is completely absorbed after oral administration and a suggested maintenance dose for adults with epilepsy is $200-400$ mg twice daily. ${ }^{171}$ Eisen et al. have recently used lamotrigine in a double blind, placebo controlled trial of 67 patients with ALS in a dose of $100 \mathrm{mg} /$ day. ${ }^{172}$ There was no significant improvement in survival, which was the chief end point. The dose may have been too small and repeat trials using up to $400 \mathrm{mg} /$ day are warranted. There has also been one recently reported negative trial using dextromethorphan, an NMDA receptor antagonist. ${ }^{173}$ Fourteen patients were treated with $150 \mathrm{mg}$ or placebo in a double-blind crossover trial with a wash out period of 4 weeks between the two treatment periods. Thereafter, surviving patients were treated with $300 \mathrm{mg}$ dextromethorphan daily for up to 6 months in an open trial. Others trials with dextromethorphan are underway. Riluzole (amino-2-trifluoromethoxy-6benzothiazine) is another glutamate antagonist which probably inhibits glutamate release. Given in a dose of $100 \mathrm{mg} /$ day it has been shown to have significant effect on survival in a preliminary trial of 155 patients with ALS. The effect was greatest in patients with bulbar onset (V. Meininger - Personal Communication). A larger multinational, multicentre trial is presently underway.

Therapy with antioxidants has not undergone controlled trials. However, there are ongoing controlled trials with deprenyl $5-10 \mathrm{mg} /$ day. It and vitamin E 400-800 iu are presently the only antioxidants used for these studies.

Therapeutic approaches to ALS have invariably used single therapy. Single therapy is important to determine the efficacy of a specific remedy. However, in a disease as complex as ALS it might be more pragmatic to approach therapy in terms of what is understood of its pathogenic mechanisms. This would require multitherapy, an approach that has been successful in other disorders, especially cancer.

\section{ACKNOWLEDGEMENTS}

Supported in part by MRC Program Grant PG-11127(AE). CK holds a scholarship from the MRC.

\section{REFERENCES}

1. Charcot JM. Sclerose des cordons lateraux de la moelle épinère chez femme hysterique atteinte de contracture permanente des quatre membres. Bull Soc Med Hop Paris. 1865; 2 (Suppl 2): 24-42.

2. Charcot JM, Joffroy A. Deux cas datrophie musculaire progressive avec lesions de la substance grise et des faisceaux anteriolateraux de la moelle épinère. Arch Physiol Norm Pathol 1869 ; 2: 354-367, 629-649, 744-760.

3. Gaffney JS, Sufit RL, Hartmann H, et al. Clinical diagnosis of amyotrophic lateral sclerosis (ALS): a clinicopathological study of "El Escorial" working group criteria in 36 autopsied patients. Neurology 1992; 42 (Suppl 3): 455p.

4. Li TM, Swash M, Alberman E, Day SJ. Diagnosis of motor neuron disease by neurologists: a study in three countries. J Neurol Neurosurg Psychiatry 1991; 54: 980-983.

5. Daube J. Electrophysiological studies in the diagnosis and prognosis of motor neuron diseases. Neurol Clin 1985; 3:473-493.

6. Eisen A, McComas AJ. Motor neuron disorders. In: Clinical Electromyography, Second Edition. Brown WF, Bolton CF, eds. Boston, Butterworth-Heinemann, 1993; 427-450.

7. Younger DS, Chou S, Hays AP, et al. Primary lateral sclerosis. A clinical diagnosis reemerges. Arch Neurol 1988; 45: 1304-1307.

8. Pringle CE, Hudson AJ, Munoz DG, et al. Primary lateral sclerosis. Clinical features, neuropathology and diagnostic criteria. Brain 1992; 115: 495-520. 
9. Brown WF, Ebers GC, Hudson AJ, et al. Motor-evoked responses in primary lateral sclerosis. Muscle Nerve 1992; 15: 626-629.

10. Younger DS, Rowland LP, Latov N, et al. Lymphoma, motor neuron diseases and amyotrophic lateral sclerosis. Ann Neurol 1991; 29: 78-86.

11. Parry GJ, Sumner AJ. Multifocal motor neuropathy. Neurol Clin 1992; 10: 671-684

12. Hudson AJ. Amyotrophic lateral sclerosis and its association with dementia, Parkinsonism and other neurological disorders: a review. Brain 1981; 104: 217-247.

13. Eisen A, Calne D. Amyotrophic lateral sclerosis, Parkinson's disease and Alzheimer's disease: phylogenetic disorders of the human neocortex sharing many characteristics. Can J Neurol Sci 1992; 19 (Suppl 1): 117-123.

14. Burrow JNC, Blumbergs PC. Substantia nigra degeneration in motor neurone disease: a quantitative study. Aust NZ J Med 1992; 22: 469-472.

15. Hasegawa K, Kowa H, Yagishita S. Extrapyramidal system involvement in motor neuron disease. J Neurol Sci 1992; 108: 137-148.

16. Hawkes $\mathrm{CH}$, Graham AJ. National UK motor neuron disease twin study using the death discordant approach. Ann Neurol 1992; 32: $272-273$

17. Siddique T, Figlewicz DA, Pericak-Vance MA, et al. Linkage of a gene causing familial amyotrophic lateral sclerosis to chromosome 21 and evidence of a genetic-locus heterogeneity. $\mathrm{N}$ Engl J Med 1991: 324: 1381-1384.

18. Rosen DR, Siddique T, Patterson D, et al. Mutations in $\mathrm{Cu} / \mathrm{Zn}$ superoxide dismutase gene are associated with familial amyotrophic lateral sclerosis. Nature 1993; 362: 59-62.

19. Monti D, Troiano L, Tropea F, et al. Apoptosis- programmed cell death: a role in the aging process? Am J Clin Nutrition 1992; 55 (Suppl 6): 1208-1214.

20. Fahn S, Cohen G. The oxidant stress hypothesis in Parkinson's disease: evidence supporting it. Ann Neurol 1992; 32: 804-812.

21. Eubanks JH, Puranam RS, Kleckner NW, et al. The gene encoding the glutamate receptor subunit GluR5 is located on human chromosome 21 q $21.1-22.1$ in the vicinity of the gene for familial amyotrophic lateral sclerosis. Proc Natl Acad Sci USA 1993; 90: 178-182.

22. Couratier P, Hugon J, Sindu P, Vallat JM, Dumas M. Cell culture evidence for neuronal degeneration in amyotrophic lateral sclerosis being linked to glutamate $\mathrm{AMPA} / \mathrm{k}$ ainate receptors. Lancet 1993; 341: 265-268.

23. Jokelainen M. Amyotrophic lateral sclerosis in Finland. Adv Exp Med Biol 1987; 209: 341-344.

24. Lilienfeld DE, Chan E, Ehland et al. Increasing mortality from motor neuron disease in the United States during the past two decades. Lancet 1989;1: 710-713.

25. Durrleman S, Alprerovitch A. Increasing trend of ALS in France and elsewhere: are changes real? Neurology 1989;29: 13061309.

26. Gunnarsson L, Lindberg G, Soderfelt B, et al. The mortality of motor neuron disease on Sweden. Arch Neurol 1990; 47: 42-46.

27. Kurtzke JF. Risk factors in amyotrophic lateral sclerosis. In: Advances in Neurology, Vol 56: Amyotrophic Lateral Sclerosis and Other Motor Neuron Diseases. Rowland LP, ed. Raven Press Lid. 1991; 245-270.

28. Chio A, Meineri P, Tribolo A, Schiffer D. Risk factors in motor neuron disease: a case control study. Neuroepidemiology 1991; 10: 174-184

29. Gallagher JP, Talbert OR. Motor neuron syndrome after electric shock. Acta Neurologica Scand 1991; 83: 79-82.

30. Sirdofsky MD, Hawley RJ, Manz H. Progressive motor neuron disease associated with electrical injury. Muscle Nerve 1991 14: $997-980$.

31. Gregoire N, Serratrice G. Risk factors in amytotrophic lateral sclerosis. Initial results apropos of 35 cases. Revue Neurol 1991; 147: $706-713$

32. Longstreth WT, Nelson LM, Koepsell TD, van Belle G. Hypotheses to explain the association between vigorous physical activity and amyotrophic lateral sclerosis. Medical Hypotheses 1991; 34: $144-148$
33. Currier RD, Conwill DE, Jackson MS. Is amyotrophic lateral sclerosis caused by influenza and physical activity? Results of a Iwin study. Ann Neurol 1988; 24: 148p.

34. Armon C, Kurland LT, Daube JR, O'Brien PC. Epidemiologic correlates of sporadic amyotrophic lateral sclerosis. Neurology 1991; 41: 1077-1084.

35. Kurland LT, Radhakrishnan K, Smith GE, et al. Mechanical trauma as a risk factor in classic amyotrophic lateral sclerosis: lack of epidemiological evidence. J Neurol Sci 1992; 113: 133-143.

36. Olivares L, San Esteban E, Alter M. Mexican 'resistance' to amyotrophic lateral sclerosis. Arch Neurol 1972; 27: 397-402.

37. Annegers JF, Appel S, Lee JR, Perkins P. Incidence and prevalence of amytrophic lateral sclerosis in Harris County, Texas, 1985-1988. Arch Neurol 1991; 48: 589-593.

38. Williams DB, Steele J, Craig UK et al. Changing prevelance of amyotrophic lateral sclerosis and Parkinsonism-dementia complex on Guam and the Northern Mariana Islands. Ann Neurol 1992; 32: 252p.

39. Kato S, Hirano A, Llena JF, et al. Ultrastructural identification of neurofibrillary tangles in the spinal cords of Guamanian amyotrophic lateral sclerosis and parkinsonism-dementia complex on Gaum. Acta Neuropath 1992; 83: 277-282.

40. Sienko DG, Davis JP, Taylor JA, Brooks BR. Amyotrophic lateral sclerosis. A case-control study following detection of a cluster in a small Wisconsin community. Arch Neurol 1990: 47: 38-4I.

41. Taylor JA, Davis JP. Evidence for clustering of amyotrophic lateral sclerosis in Wisconsin. J Clin Epidemiol 1989; 42: 569-575.

42. Proctor SP, Feldman RG, Wolf PA, et al. A perceived cluster of amyotrophic lateral sclerosis cases in a Massachusetts community. Neuroepidemiology 1992; 11: 277-281.

43. Appel SH. Unifying hypothesis for the cause of amyotrophic lateral sclerosis, Parkinsonism and Alzheimer disease. Ann Neurol 1981; 10: 499-505

44. Chou SM, Norris FH. Amyotrophic lateral sclerosis: the lower motor neuron hypothesis. Muscle \& Nerve 1993; 16: (in press).

45. Charcot JM. Clinical Lectures on Diseases of the Nervous System. Vol III (translated by Savill T), The New Sydenham Society. London, 1889; 164-182.

46. Hudson AJ, Kiernan JA. Letter to the Lancet. Lancet 1988; 1: 652.

47. Eisen A, Kim S, Pant B. Amyotrophic lateral sclerosis (ALS): a phylogenetic disease of the corticomotoneuron. Muscle Nerve 1992; 15: 219-228

48. Rapport MM. Implications of altered brain ganglioside profiles in amyotrophic lateral sclerosis (ALS). Acta Neurobiol Experiment 1990; 50: 505-513.

49. Oba H, Araki T, Monzawa S, et al. MR imaging of anyotrophic lateral sclerosis. Nippon Acta Radiol 1992; 52: 427-435.

50. Ishikawa K. Nagura H, Yokota T, Yamanouchi H. Signal loss in the motor cortex on magnetic: Images in amyotrophic lateral sclerosis. Ann Neurol 1993; 33: 218-222.

51. Kiernan JA, Hudson AJ. Changes in sizes of cortical and lower motor neurons in amyotrophic lateral sclerosis. Brain 1991: 114: 843-853.

52. Porter R. Corticomotoneuronal projections: synaptic events related to skilled movement. Proc R Soc Lond (Biol) 1987; 231: 147-168.

53. Sillevis-Smitt PAE, de Jong JMBV. Animal models of amyotrophic lateral sclerosis and the spinal muscular atrophies. J Neurol Sci 1989; 91: 231-258.

54. Cote F, Collard JF, Julien JP. Progressive neuronopathy in transgenic mice expressing the human neurofilament heavy gene: a mouse model of amyotrophic lateral sclerosis. Cell 1993: 73: $35-46$.

55. Iwatsubo T, Kuzuhara S, Kanemitsu A, et al. Corticofugal projections to the motor nuclei of the brainstem and spinal cord in humans. Neurology 1990; 40: 309-312.

56. Kihira T, Yoshida S, Uebayashi Y, et al. Involvement of Onuf's nucleus in ALS. Demonstration of intraneuronal conglomerate inclusions and Bunina bodies. J Neurol Sci 1991; 104: 119-128.

57. Okamoto K, Hirai S, Ishiguro K, et al. Light and electron microscopic and immunohistochemical observations of Onuf's nucleus of amyotrophic lateral sclerosis. Acta Neuropathol 1991; $81: 610-614$. 
58. Shaw PJ, Ince PG, Johnson M, et al. The quantitative autoradiographic distribution of $\left[{ }^{3} \mathrm{H}\right] \mathrm{MK}-801$ binding sites in the normal human brainstem in relation to motor neuron disease. Brain Res 1992; 572: 276-280.

59. Carpenter $\mathrm{S}$. Proximal axonal enlargement in motor neuron disease. Neurology 1968; 18: 841-851.

60. Delisle MB, Carpenter S. Neurofibrillary axonal swellings and amyotrophic lateral sclerosis. J Neurol Sci 1984; 63: 241-252.

61. Okamoto K, Hirai S, Shoji M, et al. Axonal swellings in the corticospinal tracts in amyotrophic Lateral Sclerosis. Acta Neuropathol 1990; 80: 222-226.

62. Sasaki S, Maruyama S. Increase in diameter of the axonal initial segment is an early change in amyotrophic Lateral Sclerosis. J Neurol Sci 1992; 110: 114-120.

63. Leigh PN, Dodson A, Swash M, et al. Cytoskeletal abnormalities in motor neuron disease: an immunocytochemical study. Brain 1989; 112: 521-535.

64. Breuer AC, Atkinson MB, Margolis RL. The neuronal cytoskeleton and axonal transport abnormalities in motor neuron disease. III: Smith RA, ed. Handbook of Amyotrophic Lateral Sclerosis. New York: Marcel Dekker Inc., 1992: 503-517.

65. Leigh PN, Swash M. Cytoskeletal pathology in motor neuron diseases. In: Advances in Neurology. Vol 56: Amyotrophic Lateral Sclerosis and Other Motor Neuron Diseases. Rowland LP, ed. Raven Press Ltd, 1991; 115-124.

66. Hirano A. Cytopathology of amyotrophic lateral sclerosis. In: Rowland LP, ed. Adv. Neurology, vol 56. New York: Raven Press, 1991: 91-102.

67. Brady ST. Motor neurons and neurofilaments in sickness and in health. Cell 1993; 73: 1-3.

68. Monteiro MJ, Hoffman PN, Gearhart JD, Cleveland DW. Expression of NF-L in both neuronal and nonneuronal cells of transgenic mice: increased neurofilament density in axons without affecting caliber. J Cell Biol 1990; 111: 1543-1557.

69. Xu Z, Cork LC, Griffin JW, Cleveland DW. Increased expression of neurofilament subunit NF-L produces morphological alterations that resemble the pathology of human motor neuron disease. Cell 1993; 73: 23-33.

70. Mitsumoto $\mathrm{H}$, Bradley WG. Murine motor neuron disease (the wobbler mouse). Brain 1982; 105: 811-834.

71. Messer A, Strominger NL, Mazurkiewicz JE. Histopathology of the late-onset motor neuron degeneration (Mnd) mutant in the mouse. J Neurogenet 1987; 4: 201-213.

72. Karpati G, Carpenter S, Durham H. A hypothesis for the pathogenesis of amyotrophic lateral sclerosis. Rev Neurol 1988; 144: 672-675.

73. Parhad IM, Oishi R, Clark AW. GAP-43 gene expression is increased in anterior horn cells of amyotrophic lateral sclerosis. Ann Neurol 1992; 31: 593-597.

74. Wakayama I. Morphometry of spinal motor neurons in amyotrophic lateral sclerosis with special reference to chromatolysis and intracytoplasmic inclusion bodies. Brain Res 1992; 586: 12-18.

75. Lowe J, Aldridge $F$, Lennox G, et al. Inclusion bodies in motor cortex and brainstem of patients with motor neurone disease are detected by immunocytochemical localization of ubiquitin. Neurosci Lett 1989; 105: 7-13.

76. Garofalo O, Kennedy PG, Swash M, et al. Ubiquitin and heat shock protein expression in amyotrophic lateral sclerosis. Neuropathol Appl Neurobiol 1991; 17: 39-45.

77. Leigh PN, Whitwell H, Garofalo O, et al. Ubiquitin-immunoreactive intraneuronal inclusions in amyotrophic lateral sclerosis. Morphology. distribution and specificity. Brain 1991; 114: 775788.

78. Murayama S, Bouldin TW, Suzuki K. Immunocytochemical and ultrastructural studies of upper motor neurons in amyotrophic lateral sclerosis. Acta Neuropathol 1992; 83: 518-524.

79. Okamoto K. Hirai S, Yamazaki T, et al. New ubiquitin-positive intraneuronal inclusions in the extra-motor cortices in patients with amyotrophic lateral sclerosis. Neurosci Lett 1991; 129: 233-236.

80. Matsumoto S, Hirano A, Goto S. Ubiquitin -immunoreactive filamentous inclusions in anterior horn cells of Guamanian amyotrophic lateral sclerosis. Acta Neuropathol 1990; 80: 233-238.
81. Brooks BR. The role of axonal transport in neurodegenerative disease spread: meta-analysis of experimental and clinical poliomyelitis compared with amyotrophic lateral sclerosis. Can J Neurol Sci 1991; I8 (Suppl) 435-438.

82. Sar M, Stumpf WE. Androgen concentration in motor neurons of cranial nerves and spinal cord. Science 1992; 197: 77-80.

83. Sheridan PJ, Weaker FJ. Androgen receptor systems in the brain stem of the primate. Brain Res 1987; 406: 62-72.

84. Warner CL, Griffin JE, Wilson JD, et al. X-linked spinomuscular atrophy: a kindred with associated abnormal androgen receptor binding. Neurology 1992; 42: 2181-2184.

85. Igarashi $\mathrm{S}$, Tanno Y, Onodera $\mathrm{O}$, et al. Strong correlation between the number of CAG repeats in androgen receptor genes and the clinical onset of features of spinal and bulbar muscular atrophy. Neurology 1992; 42: 2300-2302.

86. Ono S, Yamauchi M. Collagen cross-linking of skin in patients with amyotrophic lateral sclerosis. Ann Neurol 1992; 31: 305-310.

87. Ono S, Yamauchi M. Amyotrophic lateral sclerosis: increased solubility of skin collagen. Neurology 1992; 42: 1535-1539.

88. Shaw PJ. Excitatory amino acid receptors, excitotoxicity, and the human nervous system. Current Opinion in Neurology and Neurosurgery 1993; 6: 414-422.

89. Choi DW. Glutamate Neurotoxicity and Diseases of the Nervous System. Neuron 1988; 1: 623-634.

90. Choi DW, Rothman SM. The role of glutamate neurotoxicity in hypoxic-ischemic neuronal death. Ann Rev Neurosci 1990; 13: $171-182$.

91. Rothman, SM. Excitotoxins: Possible mechanisms of action. NY Acad Sci 1992; 648: 132-138.

92. Nicotera P, Orrenius S. Ca2+ and cell death. NY Acad Sci 1992; 648: 17-27.

93. Konnerth A, Keller BU, Lev-Tov A. Patch clamp analysis of excitatory synapses in mammalian spinal cord slices. Pflugers Arch 1990; 417: 285-290.

94. Ziskind-Conhaim L. NMDA receptors mediate poly- and monosynaptic potentials in motoneurons of rat embryos. J Neurosci 1990; 10: 125-135

95. Cornell-Bell AH, Finkbeiner SM, Cooper MS, Smith SJ. Glutamate induces calcium waves in cultured astrocytes: longrange glial signalling. Science 1990; 247: 470-473.

96. Plaitakis A, Caroscio JT. Abnormal glutamate metabolism in amyotrophic lateral sclerosis. Ann Neurol 1987; 22: 575-579.

97. Plaitakis A. Glutamate dysfunction and selective motor neuron degeneration in amyotrophic lateral sclerosis: A hypothesis. Ann Neurol 1990; 28: 3-8.

98. Spencer PS, Nunn PB, Hugon J, et al. Guam amyotrophic lateral sclerosis-Parkinsonism-dementia linked to a plant excitant neurotoxin. Science 1987; 237: 517-522.

99. Rothstein JD, Tsai G, Kuncl RW, et al. Abnormal excitatory amino acid metabolism in amyotrophic lateral sclerosis. Ann Neurol 1990; 28: 18-25.

100. Rothstein JD, Kuncl R, Chaudhry V, et al. Excitatory amino acids in amyotrophic lateral sclerosis: An update. Ann Neurol 1991; 30: 224-225.

101. Heafield MT, Fearn S, Steventon RH, et al. Plasma cysteine and sulphate levels in patients with motor neurone, Parkinson's and Alzheimer's disease. Neurosci Lett 1990; 1 10: 216-220.

102. Perry TL, Krieger C, Hansen S, Eisen A. Amyotrophic lateral sclerosis: amino acid levels in plasma and cerebrospinal fluid. Ann Neurol 1990; 28: 12-17.

103. Perry TL, Krieger C, Hansen S, Tabatabaei A. Amyotrophic lateral sclerosis: fasting plasma levels of cysteine and inorganic sulfate are normal, as are brain contents of cysteine. Neurology 1991; 41: 487-490.

104. Cottell E, Hutchinson M, Simon J, Harrington MG. Plasma glutamate levels in normal subjects and in patients with amyotrophic lateral sclerosis. Biochem Soc Trans 1990; 18: 283.

105. Spink DC, Martin DL. Excitatory amino acids in amyotrophic lateral sclerosis. Ann Neurol 1991; 29: 110.

106. Hugon J, Vallat JM, Spencer PS, et al. Kainic acid induces early and delayed degenerative neuronal changes in rat spinal cord. Neurosci Lett 1989; 104: 258-262.

107. Urca G, Urca R. Neurotoxic effects of excitatory amino acids in the mouse spinal cord: quisqualate and kainate but not $\mathrm{N}$ methyl-D-aspartate induce permanent neural damage. Brain Res 1990; 529: 7-15. 
108. Teitelbaum JS, Zatorre RJ, Carpenter S, et al. Neurological sequelae of domic acid intoxication due to the ingestion of contaminated mussels. N Engl J Med 1990; 322: 1781-1787.

109. Debonnel G, Beauchesne L, de Montigny C. Domoic acid, the alleged "mussel toxin", might produce its neurotoxic effect through kainate receptor activation: an electrophysiological study in the dorsal hippocampus. Can J Phys Pharm 1989; 67: 29-33.

110. Perry TL, Hansen S, Jones K. Brain glutamate deficiency in amyotrophic lateral sclerosis. Neurology 1987; 37: 1845-1848.

111. Malessa S, Leigh PN, Bertel O, et al. Amyotrophic lateral sclerosis: glutamate dehydrogenase and transmitter amino acids in spinal cord. J Neurol Neurosurg Psychiatry 1991; 54: 984-988.

112. Plaitakis A, Constantakakis E, Smith J. The neuroexcitotoxic amino acids glutamate and aspartate are altered in the spinal cord and brain in amyotrophic lateral sclerosis. Ann Neurol 1988; $24: 446-449$.

113. Tsai GC, Stauch-Slusher B, Sim L, et al. Reduction in acidic amino and $\mathrm{N}$-acetylaspartylglutamate in amyotrophic lateral sclerosis CNS. Brain Res 1991; 556: 151-156.

114. Allaoua H, Chaudieu I, Krieger C, et. al. Alterations in spinal cord excitatory amino acid receptors in amyotrophic lateral sclerosis patients. Brain Res 1992; 579: 169-172.

115. Shaw PJ, Ince PG, Johnson M, et al. The quantitative autoradiographic distribution of $\left[{ }^{3} \mathrm{H}\right] \mathrm{MK}-801$ binding sites in the normal human spinal cord. Brain Res 1991; 539: 164-168.

116. Rothstein JD, Martin LJ, Kuncl RW. Decreased glutamate transport by the brain and spinal cord in amyotrophic lateral sclerosis. N Engl J Med 1992; 326: 1464-1468.

117. Young AB, Fagg GE. Excitatory amino acid receptors in the brain: membrane binding and receptor autoradiographic approaches. Trends Pharm Sci 1990; 11: 126-133.

118. Whitehouse PJ, Walmsley JK, Zarbin MA, et al. Amyotrophic lateral sclerosis: alterations in neurotransmitter receptors. Ann Neurol 1983; 14:8-16.

119. Krieger C, Perry TL, Hansen S, Mitsumoto H, Honoré, T. Excitatory amino acid receptor antagonist in murine motoneuron disease (the wobbler mouse). Can J Neurol Sci 1992; 19 : 462-465.

120. Pestronk A. Invited review: motor neuropathies, motor neuron disorders and antiglycolipid antibodies. Muscle Nerve 1991; 14: 297-936.

121. Krieger C. Perry TL, Ziltener HJ. Amyotrophic lateral sclerosis: interleukin-6 levels in cerebrospinal fluid. Can J Neurol Sci 1992; 19: 357.359.

122. Drachman DB, Kuncl RW. Amyotrophic lateral sclerosis: an unconventional autoimmune disease? Ann Neurol 1989; 26: 269-274.

123. McGeer PL, McGeer EG, Kawamata T, et al. Reactions of the immune system in chronic degenerative neurological diseases. Can J Neurol Sci 1991; 18 (Suppl): 376-379.

124. Engelhardt JI, Appel SH. IgG reactivity in the spinal cord and motor cortex in amyotrophic lateral sclerosis. Arch Neurol 1990; 47: 1210-1216

125. Lampson LA, Kushner PD, Sobel RA. Major histocompatibility complex antigen expression in the affected tissues in amyotrophic lateral sclerosis. Ann Neurol 1990; 28: 365-372.

126. Kawamata T, Akiyama H, Yamada T, McGeer PL. Immunologic reactions in amyotrophic lateral sclerosis brian and spinal cord tissue. Am J Path 1992; 140: 691-707.

127. Murayama $S$, Inoue $K$, Kawakami $\mathrm{H}$, el al. A unique pattern of astrocytosis in the primary motor area in amyotrophic lateral sclerosis. Acta Neuropathol 1991; 82: 456-461.

128. Engelhardt JL, Appel SH, Killian JM. Experimental autoimmune motorneuron disease. Ann Neurol 1989; 26: 368-376.

129. Engelhardt JL, Appel SH, Killian JM. Motor neuron destruction in guinea pigs immunized with bovine spinal cord ventral horn homogenate: experimental autoimmune gray matter disease. J Neuroimmunol 1990; 27: 21-31.

130. Uchitel OD, Scornik F, Protti DA, et al. Long-term neuromuscular dysfunction produced by passive transfer of amyotrophic lateral sclerosis immunoglobulins. Neurology 1992; 42: 2175-2180.

131. Delbono O, Garcia J, Appel SH, Stefani E. IgG from amyotrophic lateral sclerosis affects tubular calcium channels of skeletal muscle. Am J Physiol 1991: 260: 1347-1351.
132. Smith RG, Hamilton S, Hofmann F. Schneider T, et al. Serum antibodies to L-type calcium channels in patients with amyotrophic lateral sclerosis. N Engl J Med 1992; 327: 1721-1728.

133. Rowland LP. Amyotrophic lateral sclerosis and autoimmunity. $N$ Engl J Med 1992; 327: 1752-1753.

134. Ince P, Stout N, Slade J, Shaw PJ. Calcium binding protein immunoreactivity in human motor system and in motor neurone disease. Proc 1st Intl ALS/MND meeting, Birmingham. U.K., 1991.

135. Barry MA, Eastman A. Endonucleuse activation during apoptosis: the role of cytosolic $\mathrm{Ca} 2+$ and $\mathrm{pH}$. Biochem Biophysical Res Comm 1992; 186: 782-789.

136. Franceschi C. Cell proliferation, cell death and aging. Aging 1992; 1: 1-13.

137. Altman J. Programmed cell death: the paths to suicide. Trends Neurosci 1992; 15.

138. Alsion MR, Sarraf CE. Apoptosis: a gene-directed progranme of cell death. J Roy Coll Physcians Lond 1992; 26: 25-35

139. Trump BF, Berezesky IK. The role of cytosolic Ca2+ in cell injury, necrosis and apoptosis. Current Opinion Cell Biol 1992: 4: $227-232$

140. Stewart SS, Appel SH. Trophic factors in neurological disease. Ann Rev Med 1988; 39: 193-201.

141. Oppenheim RW. The neurotrophic theory and naturally occurring motoneuron death. Trends Neurosci 1989; 12: 252-255.

142. Barde YA. Trophic factors and neuronal survival. Neuron 1989; 2: 1525-1534.

143. Oppenheim RW. Cell death during development of the nervous system. Ann Rev Neurosci 1991; 14: 453-501.

144. Kim SU, Krieger C, Eisen A. Human and rodent spinal cord neurons in culture. In: Rowland LP, ed. Advances in Neurology, Vol 56: Amyotrophic Lateral Sclerosis and Other Motor Neuron Diseases. Raven Press Ltd. 1991; 57-67.

145. Dohrmann U, Edgar D, Thoenen H. Distinct neurotrophic factors from skeletal muscle and the central nervous system interact synergistically to support the survival of cultured embryonic spinal motor neurons. Dev Biol 1987; 124: 145-152.

146. Arakawa Y, Sendtner M, Thoenen H. Survival effect of ciliary neurotrophic factor (CNTF) on chick embryonic motoneurons in culture: comparison with other neurotrophic factors and cytokines. J Neurosci 1990; 10: 3507-3515.

147. Martinou J-C, Martinou I, Kato AC. Cholinergic differentiation factor (CDF/LIF) promotes survival of isolated rat embryonic motoneurons in vitro. Neuron 1992; 8: 737-744.

148. Oppenheim RW, Prevette D, Yin QW, et al. Control of embryogenic motorneuron survival in vivo by ciliary neurotrophic factor. Science 1991; 251: 1616-1618

149. Davis S, Aldrich TH, Valenzuela DM, et al. The receptor for ciliary neurotrophic factor. Science 1991; 253: 59-63.

150. Ip NY, Nye SH, Boulton TG, et al. CNTF and LIF act on neuronal cells via shared signaling pathways that involve the IL-6 signal transucing receptor component gp130. Cell 1992; 69: 1121-1132.

151. Ip NY, McClain J. Barrezueta NX, et al. The component of the CNTF receptor is required for signaling and defines potential CNTF targets in the adult and during development. Neuron 1993; 10: 89-102.

152. Stockli KA, Lillien LE, Naher-Noe M, et al. Regional distribution, developmental changes and cellular localization of CNTF. mRNA and protein in the rat brain. J Cell Biol 1991; 115: 447. 459

153. Sendtner M, Schmalbruch H, Stockli KA. et al. Ciliary neurotrophic factor prevents degeneration of motor neurons in mouse mutant progressive motor neuronopathy. Nature 1992: 358 : $501-504$

154. Friedman B, Scherer SS, Rudge JS, Helgren M, et al. Regulation of ciliary neurotrophic factor expression in myelin-related Schwann cells in vivo. Neuron 1992; 9: 295-305.

155. Mitsumoto $\mathrm{H}$, Ikeda $\mathrm{K}$. Ciliary neurotrophic factor (CNTF) improves neuromuscular function and muscle strength following onset of motor neuron disease in the wobbler mouse. Neurolgy 1993; 43 (Suppl): 415p. 
156. Ikeda K, Mitsumoto $H$. Morphological changes correlate with functional improvement following ciliary neurotrophic factor (CNTF) treatment of motor neuron disease in the wobbler mouse. Neurology 1993; 43 (Suppl): 32 lp.

157. ALS CNTF Treatment Study (ACTS) Phase I-II Study Group. Recombinant human ciliary neurotrophic factor (rHCNTF) in amyotrophic lateral sclerosis (ALS) patients: phase I-II safety, tolerability and pharmacokinetic studies. Neurology 1993; 43 (Suppl): $416 \mathrm{p}$.

158. Bloch-Gallego E, Huchet M, El M'Hamdi, et al. Survival in vitro of motoneurons identified or purified by novel antibody-based methods is selectively enhanced by muscle-derived factors. Development 1991; 111: 221-232.

159. Jubelt B. Viruses and motor neuron disease. In: Rowland LP, ed Advances in Neurology, Vol.56: Amyotrophic Lateral Sclerosis and Other Motor Neuron Diseases. Raven Press Lid. 1991; 463472

160. Salazar AM, Masters CL, Gajdusek DC, Gibbs CJ Jr. Syndromes of amyotrophic lateral sclerosis and dementia: relation to transmissible Creutzfeldt-Jakob disease. Ann Neurol 1983; 14: 17-26.

161. Melchers $W$, de Visser $M$, Jongen $P$, et al. The postpolio syndrome: no evidence for poliovirus persistence. Ann Neurol 1992; 32: 728-732.

162. Mitchell JD. Anterior horn cell diseases. In: Diseases of the Spinal Cord. Critchley E, Eisen A, eds. Springer-Verlag, London, 1991; 235-253.

163. Gajdusek DC, Salazar AM. Amyotrophic lateral sclerosis and parkinsonian syndromes in high incidence among Auyu and Jakai people of West New Guinea. Neurology 1982; 32: 107-126.

164. Yanagihara RT, Garruto RM, Gajdusek DC, et al. Calcium and vitamin D metabolism in Guamian Chamorrros with amyotrophic lateral sclerosis and parkinsonism-dementia. Ann Neurol 1984; 15: 42-48.
165. Yasui M, Yase Y, Ota K, Garruto RM. Aluminum deposition in the central nervous system of patients with amyotrophic lateral sclerosis from the Kii Peninsula of Japan. Neurotoxicology 1991; 12: 615-620.

166. Yoshida S, Yase Y, Mizumoto Y, Iwata S. Aluminum deposition and Ca-hydroxyapatite formation in frontal cortex tissue of amyotrophic lateral sclerosis. Clin Neurol 1989; 29: 421-426.

167. Mitchell JD, East BW, Harris IA, Pentland B. Manganese, selenium and other trace elements in spinal cord, liver and bone in motor neurone disease. Eur Neurol 1991; 31: 7-11.

168. Yasui M, Yase Y, Ota K, Mukoyama M, Adachi K. High aluminum deposition in the central nervous system of patients with amyotrophic lateral sclerosis from the Kii Peninsula, Japan: two cases. Neurotoxicology 1991; 12: 277-283.

169. Garruto RM, Shankar SK, Yanaguhara R, et al. Low-calcium, high aluminum diet-induced motor neuron pathology in cynomolgus monkeys. Acta Neuropathol (Berl) 1989; 78: 210-219.

170. Strong MJ, Garruto RM. Potentiation in the neurotoxic induction of experimental chronic neurodegenerative disorders: $\mathrm{N}$-butyl benzenesulfonamide and aluminum chloride. Neurotoxicology 1991; 12: 415-425.

171. Brodie MJ. Drug profiles: lamotrigine. Lancet 1992; 339: 1397. 1400.

172. Eisen A, Stewart H, Schulzer M, Cameron D. Anti-Glutamate therapy in amyotrophic lateral sclerosis: a trial using lamotrigine. Can J Neurol Sci (in press).

173. Asmark H, Aquilonius SM, Gillberg PG, et al. A pilot trial of dextromethorphan in amyotrophic lateral sclerosis. J Neurol Neurosurg Psychiatry 1993; 56: 197-200. 